IOSR Journal of Pharmacy

ISSN: 2250-3013, www.iosrphr.org

\||| Volume 2 Issue 5 ||| Sep-Oct 2012 ||| PP.01-03

\title{
Prevalenceof vitamin b12 deficiency in highersocio-economical class ofbhuj-kutch.
}

\author{
Dr. Harshid L. Patel ${ }^{1}$, Dr. Sharad K.Gor ${ }^{1}$,Dr. Amit M Shah ${ }^{2}$, Dr. Jatin Dhanani ${ }^{2}$ \\ ${ }^{1}$ Assistant Professor, Department of Pathology, Gujarat Adani Institute of Medical Sciences, Bhuj \\ ${ }^{2}$ Assistant Professor, Dept.Of Pharmacology, Gujarat Adani Institute of Medical Sciences, Bhuj.
}

\begin{abstract}
Background-Vitamin B12, also called Cobalamin, is a water-soluble vitamin with a key role in the normal functioning of the brain and nervous system, formation of red blood cells andsynthesis of DNA. Vitamin B12 deficiency is characterized by megaloblastic anemia, fatigue, weakness, and neurological changes, such as numbness and tingling in the hands and feet. Therefore early and reliable diagnosis of Vitamin B12 deficiency is very important to avoid irreversible damage.

Aims and Objectives-The aim of present study is to find out the prevalence of vitamin B12 deficiency in well socioeconomic population of Bhuj city.

Materials and Methods-This study is carried out among the higher socio-economic class of 866 subjects of various age \& sex. These tests were carried out in Dr. Pandya Pathological Lab, Bhuj by fluorescent enzyme immunoassay.

Results-Prevalence of vitamin B12 deficiency is around 44.2\%. Most common age group to be affected by vitamin $B 12$ deficiency is 21 - 40 years. Increasing age and vegetarian diet without any animal products are main risk factor for developing vitamin B12deficiency.

Conclusions-Commonest cause for vitamin B12 deficiency is low dietary intake of milk and milk products in female, malnutrition in elders and vegetarianism.
\end{abstract}

Keywords-Cobalamindeficiency, Megaloblastic anemia, Vitamin B12

\section{INTRODUCTION}

Vitamin B12 was discovered from its relationship to the disease pernicious anemia, which is an autoimmune diseasein which a lack of intrinsic factor causes a vitamin B12 deficiency ${ }^{(1)}$.Vitamin B12 was given the name cobalamin because of the presence of cobalt.

Vitamin B12 is naturally found in animal products, including fish, meat, poultry, eggs, milk, and milk products.Vitamin B12 can be found in multivitamins, B complex vitamins and individual supplements in oral form as well as intramuscular injections.

Approximately $56 \%$ of a 1 mcg oral dose of vitamin B12 is absorbed. Vitamin B 12 absorption appears to decrease with aging, iron deficiency, and vitamin B-6 deficiency. Tobacco, ethanol and coffee prevent absorption of the vitamin ${ }^{(2)}$

Recommended Dietary Allowances (RDA)

- $\quad$ RDA for adult males $2.0 \mathrm{mcg}$

- $\quad$ RDA for adult females $2.0 \mathrm{mcg}$

- $\quad$ RDA for children 7 to 10 years $1.4 \mathrm{mcg}$

- $\quad$ RDA for infants: $0.5 \mathrm{mcg}$

- $\quad$ RDA for pregnant and lactating women $2.6 \mathrm{mcg}$ lactation.

Daily dietary requirement of vitamin B12 is same in both males and females except in pregnancy and

Vitamin B12 deficiency is characterized by megaloblastic anemia, fatigue, weakness, constipation, loss of appetite, and weight loss ${ }^{(3,4)}$. Neurological changes, such as numbness and tingling in the hands and feet, can also occur (5). Additional symptoms of vitamin B12 deficiency include difficulty maintaining balance, depression, confusion, dementia, poor memory, and soreness of the mouth or tongue ${ }^{(6) .}$ The neurological symptoms of vitamin B12 deficiency can occur without anemia, so early diagnosis and intervention is important 
Prevalence of Vitamin B12 Deficiency in HigherSocio-economical Class ofBhuj-Kutch.

to avoid irreversible damage ${ }^{(7)}$ Although you may eat a healthy diet, complete with foods rich in B12, you could still be deficient in this vitaminresponsible for several body functions.

Vitamin B12 is also used for memory loss; Alzheimer's disease; boosting mood, energy, concentration and the immune system; and slowing aging. It is also used for heart disease, breast cancer, male infertility, diabetes, depression, fatigue. For cyanide poisoning, a large amount may be given intravenously. The United States, the Food and Drug Administration approved (in 2006) the use of hydroxycobalamin for acute treatment of cyanide poisoning ${ }^{(12) .}$

Small studies and case reports suggest that $10-30 \%$ of patients who take metformin have reduced vitamin B12 absorption ${ }^{(8,9)}$. Across studies in Latin America, around 40\% of adults had deficient or marginal status of vitamin $\mathrm{B} 12^{(10)}$. The prevalence of deficient and marginal values is much higher in Asian countries, $70 \%$ in Indian adults ${ }^{(11)}$ There is lack of any studies done for people of Bhuj city.

\section{MATERIALS\& METHODS}

This is a cross sectional study, carried out among thehigher socio-economic populations of various age \& sex in Bhuj City, Gujarat, India during 1 April, 2011 to 15 July, 2012. In this study, all subjects between 10 65 years of both the sexes have been included. Informed consent was obtained from all subjects. The exclusion criteria includes (i) pregnant and lactating females (ii) those on any medication including vitamin supplements. Blood samples were collected from all 866 subjects. Then serum vitaminB12 assay was performed using the competitive Enzyme Immunoassay Method on analyzer AIA-600 (TOSOH, Japan). For this assay, AIA-PACK B12 was used.

Normal range for serum vitamin B12 level is $211-911 \mathrm{pg} / \mathrm{mL}$. So, vitamin B12 deficiency was defined at alevel below $211 \mathrm{pg} / \mathrm{mL}^{(13,14) .}$ In this study, we consider B12 level between $211-260$ as borderline, between $151-210$ asmild deficiency, between101-150 as moderate deficiency \&below 101 as severe deficiency.

\section{RESULTS}

In this study, total 866 patients were screened for serum vitamin B12 level. Out of total 866 , there were $312(36 \%)$ male \& 554 (64\%) female patients. Amongthese866 patients, $352(40.6 \%)$ were normal, $132(15.2 \%)$ were borderline \& $382(44.2 \%)$ were deficient of vitamin B12.Among these 382 deficient patient, $233(61 \%)$ have mild deficiency, $111(29 \%)$ have moderate deficiency \& $38(10 \%)$ have severe deficiency. Among these borderline\& deficient 514 patients, $20(4.0 \%)$ patients were between $10-21$ years, $218(42.4 \%)$ patients were between 21-40 years, 219(42.4\%) patients were between 41-60 years \& 57 (11.2\%) patients were $>60$ years of age.

(1) Distribution of Vitamin B12 level in total subjects according to sex.

\begin{tabular}{|c|c|c|c|c|c|c|c|}
\hline \multirow{2}{*}{ Sex } & \multirow{2}{*}{$\operatorname{Normal}(\%)$} & \multirow{2}{*}{ Borderline(\%) } & \multicolumn{4}{|c|}{ Deficient } & \multirow{2}{*}{ Total } \\
\hline & & & Mild & Mod. & Sev. & Total & \\
\hline Male & $128(41.2)$ & 45 (14.4) & 86 & 42 & 11 & $139(45.3)$ & 312 \\
\hline Female & $224(40.4)$ & 87 (15.7) & 147 & 69 & 27 & $243(43.9)$ & 554 \\
\hline Total & $352(40.6)$ & $132(15.2)$ & 233 & 111 & 38 & $382(44.2)$ & 866 \\
\hline
\end{tabular}

(2) Distribution of Vitamin B12 level in borderline and deficient subjects according to age.

\begin{tabular}{|l|l|l|l|l|l|}
\hline Age & Borderline & Mild & Moderate & Severe & Total \\
\hline $11-20$ & $10(7.6 \%)$ & $07(3.0 \%)$ & $01(1.0 \%)$ & $02(5.3 \%)$ & 20 \\
\hline $21-40$ & $53(40.4 \%)$ & $96(41.2 \%)$ & $53(47.7 \%)$ & $16(42.1 \%)$ & 218 \\
\hline $41-60$ & $54(40.8 \%)$ & $100(42.9 \%)$ & $45(40.5 \%)$ & $20(52.6 \%)$ & 219 \\
\hline $61-70$ & $15(11.4 \%)$ & $30(12.9 \%)$ & $12(10.8 \%)$ & $00(0.0 \%)$ & 57 \\
\hline Total & 132 & 233 & 111 & 38 & 514 \\
\hline
\end{tabular}


For borderline case (level between $211-260 \mathrm{pg} / \mathrm{mL}$ ), out oftotal 132 cases, 87 were female \& 45 were male subjects. Out of total 132 cases, 10 (7.6\%) subjects were between $11-20$ years age, $53(40.4 \%)$ were between 21- 40 years age, 54 (40.8\%) were between $41-60$ years age and 15(11.4\%) were more than 60 years.

For mildly deficient case (level between 151-210 pg/mL), out of total 233 cases, 147 were female \& 86 were male subjects. Out of total 233 cases, 07 (3\%) subjects were between 11-20 years age, $96(41.2 \%)$ were between 21-40 years age, $100(42.9 \%)$ were between 41-60 years age and 30(12.9\%) were more than 60 years.

For moderately deficient case (level between 101-150 pg/mL), out of total 111 cases, 69 were female $\& 42$ were male subjects. Out of total 111 cases, 01 (1\%) subjects were between $10-20$ years age, $53(47.7 \%)$ were between $21-40$ years age, $45(40.5 \%)$ were between $41-60$ years age and $12(10.8 \%)$ were more than 60 years.

For severely deficient case (level $<100 \mathrm{pg} / \mathrm{mL}$ ), out of total 38 cases, 27 were female \& 11 were male subjects. Out of total 38 cases, $02(5.3 \%)$ subjects were between 10-20years age, 16(42.1\%) were between 2140 years age, $20(52.6 \%)$ were between $41-60$ years age and $00(0 \%)$ were more than 60 years.

\section{DISCUSSION}

In the present study, mean level of vitamin B12 in 866 subjects was observed to be $480.6 \mathrm{pg} / \mathrm{mL}$. For borderline subjects, it is $231.3 \mathrm{pg} / \mathrm{mL}$. For mildly deficient subjects, it is $181.6 \mathrm{pg} / \mathrm{mL}$. For moderately deficient subjects, it is $128.8 \mathrm{pg} / \mathrm{mL}$. For severely deficient subjects, it is $80.3 \mathrm{pg} / \mathrm{mL}$.

Present study depicted that $44.2 \%$ of total subjects have(382 out of 866) vitamin B12 deficiency with level below $211 \mathrm{pg} / \mathrm{mL}$. This findings is consistence with a study (where it is $38 \%$ ) of S. Mangukiya et al. ${ }^{(15)}$

It is also observed that if cut off value is raised up to $260 \mathrm{pg} / \mathrm{mL}, 59.4 \%$ of subjects were found to be vitamin B12 deficient. This finding is also consistent with a study (where it is $70 \%$ with cut off value 350 $\mathrm{pg} / \mathrm{mL}$ ) of S.Mangukiya et al. ${ }^{(15)}$ Our findings are also consistence with a study (where it is $47 \%$ ) of Gupta AK et al ${ }^{(16)}$ carried out at Canada in South Indian Popullations.

In present study, low dietary intake of milk and milk products in females, malnutrition in elderly and vegetarianism is implicated in low and marginal level of vitamin B12. This has been alsoproved in study of Gupta $\mathrm{AK}$ et $\mathrm{al}^{(16)}$ and Antony AC. ${ }^{(17)}$

\section{CONCLUSION}

Results of our study are consistent with few otherstudies. Rates are similar among men and women, and although elderly people as well as vegetarians are at highest risk. Possible explanation for these observations is that most of the subjects eat few or no animal products. This study also raises the large public health issue. We must improve or do fortification of the diet to prevent deficiency.

\section{REFERENCES}

[1]. "Dietary Supplement Fact Sheet: Vitamin B12" Office ofDietary Supplements, National Institute of Health. Retrieved; 2011 Sep 28. Available from:URL:http://ods.od.nih.gov/factsheets/vitaminb12.

[2]. Carmel R. How I Treat Vit. B12 Deficiency. Blood.2008;112:2214-21 (PubMed Abstract)

[3]. Herbert V. Vitamin B12 in Present Knowledge inNutrition, 17th Edi.Washington DC, International Life Science Institute Press, 1996.

[4]. Bernard MA. The effect of Vit. B12deficiency on older veterans and its relationship tohealth. J Am GeriatrSoc 1998;46:1199-206.

[5]. HealtonEB.Neurological aspect of cobalamindeficiency. J.Medicine 1991;70:229-44.

[6]. Bottiglieri T. Folate, Vit. B 12 and Neuro-psychiatric disorders. Nutr Rev 1996;54:382-90.

[7]. Clarke R. Vit. B and prevention of dementia. ProcNutrSoc 2008;67:75-81 (PubMed abstract)

[8]. Byvat DR. Use of Metformin is a cause of vitaminB12 deficiency. Am Fam Physician 2004;69: 264.

[9]. Bauman WA. Increased intake of reverses the B12 Malabsorption induced byMetformin. Diabetes Care 2000;23:1227-31.

[10]. Allen LH. Folate and vitamin B12 status in theAmericans. Nutr Rev 2004;62:529-33.

[11]. Refsum H, Yajnik CS, Gadkari M. HyperhomoCysteinemia and elevated methylmelonicindicate a high prevalence of cobalamine in Asian Indians. Am J ClinNutr 2001;74:233-41.

[12]. Dart RC(2006). Hydroxocobalmin for acutecyanide poisoning: new data from preclinical and clinical studies. ClinicalToxicology44 (Suppl.1):1-3.DOI “10.1080/15563650600811607”. PMID 16990188.

[13]. Kumar S. Recurrent Seizures: An unusual manifestation of vitamin B12 deficiency. India, 2004; 52:122-123.

[14]. WHO, Nutritional Anemias. Report of a scientific group. World Health Organisation Tech Rep Ser, 1968; 405:09-10.

[15]. S. Mangukiya,Modi B, Chaurasia P, Modi K, Shah RM. Distribution of vitamin B12 level according to sociodemographic characteristics in patients of DhirajGeneral Hospital, Pipariya, Gujarat.National Jour of Med Res, 2011;1(2):54-6.

[16]. Gupta AK, Damji A, Uppaluri A. Vitamin B12deficiency prevalence among South Asian at Torronto Clinic. CanFam Physician, 2004; 50:743-7.

[17]. Antony AC. Vegetarianism and vitamin B12 deficiency. Am J ClinNutr 2003;78:3-6. 